\title{
HR branding for the forest industry: innovative practices
}

\author{
Andrey Prudnikov*, Yulia Lektorova, and Svetlana Dmitrieva \\ ${ }^{1}$ Perm National Research Polytechnic University, Department of Foreign Languages and Public Relations, 13 Professor Pozdeev st., \\ Perm, Perm Krai 614013, Russia
}

\begin{abstract}
The study examines innovative HR branding strategies for the forest industry. The need for innovation is driven by the growing influence of negative trends that complicate the reproduction of human resources within the framework of timber industry. These alarming trends are largely characteristic of both markets economically developed and developing countries. The paper presents a quantitative and qualitative analysis of HR innovations in communication policies of Russian and foreign companies. The benchmarking analysis of innovative HR branding practices enables us to build the best communication model for companies working in the forest sector of the economy.
\end{abstract}

\section{Introduction}

Economic globalization contributes to the growing strategic interest of foreign and domestic companies in the development of their HR brands. Researchers describe the concept of an HR brand as "a combination of employer's economic, psychological and emotional advantages in the market", as "a system of images, and ideas about an organization as an employer conveyed to external and internal publics", and as "a set of targeted measures to create a positive image of an employer and to attract high-quality job seekers" $[1,2,3]$.

Ultimately, benefits, images, and events are focused on the creation of a favorable and manageable image of an industrial company as an employer for current and potential employees. Potential employees may include direct job seekers, professionals from other companies, and students and graduates from secondary and higher educational institutions. A positive company's image as an employer builds the confidence and trust of employees and job seekers. The combination of these features allows an employer to recruit and retain the top job candidates and employees at the lowest cost, which contributes to the effective strategic development and growth of an organization.

Building an HR brand is the key aim of industrial enterprises. A positive experience has been gained by companies in the industrial sector including the forest industry.

The forest industry employs around 13.7 million workers worldwide that account for $0.4 \%$ of the total workforce. The top ten countries in terms of the number of employees in the sector (including three subsectors: logging, woodworking, and pulp and paper industry) include China, the USA, Brazil, Russia, India, Japan, Germany, Indonesia, Italy, and Malaysia. Employment trends in the forest industry vary across regions in the world. Thus, in recent years, the employment rate has declined in Europe and North America but has increased in Latin America and Asia. The shift in the labor market is due to automation, the abundance of cheap labor, and measures to stimulate the development of the forestry sector and attract investments.

Jobs in the forest industry can provide job seekers with a competitive income and career prospects. However, it can vary greatly. For example, studies conducted in the United States show that average wages in the sector are close to or higher than the national average. High wages in the timber industry are recorded in North America and Europe, while low wages are typical for Asia and CIS countries.

Researchers identify the following essential characteristics of the world forestry labor market:

- gender imbalance: women make up about $20 \%$ of the forestry workforce [4]. The presence of women in the industry varies from country to country and from subsector to subsector: high employment rates are determined in the paper industry, while a low proportion of the female labor force is recorded in forestry. Given the seasonality of forestry activities, their participation is usually informal and low-paid [5];

- a high level of informal employment due to illegal deforestation;

- a high degree of injury risks at work;

- personnel aging: this trend is associated with new social risks, such as changes in the pension scheme and other risks in social security systems [6];

- low level of interest in the profession among young people.

HeadHunter, an Internet recruitment agency, analyzed more than 3,840 vacancies in the forest, timber, and woodworking industry posted on hh.ru by employers

\footnotetext{
*Corresponding author: prudnikow@gmail.com
} 
from different regions of Russia in 2019. The analysis identified the following patterns for the Russian labor market:

- Job market shrinking. On the whole in Russia, the number of job offers is steadily decreasing: vacancies amounted to $65 \%$ in the 3 rd quarter of 2018 , and $14 \%$ in the 4th quarter of 2019. Two capitals Moscow and St. Petersburg offer the largest number of open vacancies, $10.6 \%$, and $10.1 \%$ respectively. Irkutsk Region (7\%), Moscow Region (6.1\%), and Perm Krai (4.8\%) are the leaders in labor demand.

- Increased competition for personnel. On average across regions, there are $3 \mathrm{CVs}$ per job offer among forestry specialists (Moscow has 5), which is several times lower than the average level of competition among job applicants.

- Growth of wages in the industry. From the 1 st to the 4 th quarter of 2019 , there was a noticeable increase in the average wage in the Russian timber industry: from 45,000 rubles to 45,977 rubles per month. The growth in St. Petersburg was higher: from 64,974 rubles to 67,272 rubles per month.

- Age shifts and gender imbalance. The proportion of male to female $\mathrm{CVs}$ is $86 \%$ male to $14 \%$ female; every fifth $\mathrm{CV}$ is from an applicant aged 46-55. Employees aged 50 and over make up $35 \%$ of the total number of employees at forestry enterprises. As a result, the annual demand for young personnel in Russia is 3 to 15 thousand people; over 7 thousand employees have to be trained and retrained [7].

Russian experts observe low interest in working in the forest industry among young people due to several reasons: lack of material incentives, lack of high-quality knowledge and skills, since the requirements for the level of training are constantly changing and the decline in the prestige of working professions [8]. Another reason is that the forestry sector does not appeal to prospective employees due to its closeness and lack of information about the industry [9]. Besides, there is a widespread bias about the conservatism of the industry and the unattractive image of employers among young people.

The current labor market in Russian and abroad confront with similar problems. The development of an effective HR branding strategy in the forestry industry is the way to successfully address them.

Backhaus and Tikoo have developed a theoretical model that describes $\mathrm{HR}$ brand as building the relationship between employer branding, corporate culture, and employee loyalty [10].

The researchers claim that employer branding holds two main intangible assets: HR brand associations and brand loyalty. Associations with employer branding create an employer image that enhances its attractiveness for job seekers. HR brand has an impact on the organizational culture and identity of a company as an employer, and increasingly contributes to the increase in employee loyalty to employer branding. All these have a positive impact on employee's productivity.
While researchers discuss a variety of algorithms and stages of building an effective HR brand, for example, they distinguish from several to dozens of stages, all of them describe HR branding as a three-step process.

First, a company develops value for employees, in other words, it offers "Employment Value Proposition (EVP)". EVP is a reflection of who the company is and what impression it creates in the market. This is the company's proposal that is addressed to current and potential employees.

The second step is to market the value proposition to external audiences, i.e., potential employees, recruitment agencies, job counselors, and others.

Following the value proposition, the third aspect of employer branding is internal branding. It incorporates the company's declared position as an employer in the internal culture. It leads to the development of employee's loyalty and commitment to the company.

Building effective HR branding for the forest industry is an important and urgent task. The industry's current global labor market trends confirm its significance. Thus, the analytical reports of the Food and Agriculture Organization of the United Nations (FAO) have revealed that even if the demand for forest products grows in the world; even if the trend is accompanied by the expansion of production facilities at enterprises, it will not result in a proportional increase of product supply in the market due to the acute shortage of workforce in the production process. This is especially true for the markets of well-developed Western European countries. Due to the hazardous and dangerous conditions of work in the forestry sector, employment is becoming less and less attractive for young people. As a result, forestry companies from such countries as Finland, France, and Sweden repeatedly complain about the lack of personnel in the industry [11].

The problems under consideration also have their downside. In the case of increasing immigration to alleviate labor shortage, it may lead to the degradation of the forest industry on the whole. Immigrants are less demanding for safe and attractive working conditions and adequate compensation, which may result in the substantial growth of environmental costs for the entire world community. One of the conditions of sustainable development of timber production is high-skilled personnel. A well-known fact is that in developing countries forestry work is traditionally carried out by predominantly low-skilled employees who work in hazardous conditions with a risk to health and life. This entails excessive waste in the course of production activities, significant damage to the environment, a high rate of accidents, and, consequently, high staff turnover. [12]. However, the timber enterprises in Western countries may experience the same problems, since they often encounter the urgency of filling job vacancies by hiring yesterday's immigrants who agree to work for a small remuneration due to their low qualifications. One of the ways to tackle the issue is to enhance the efficiency of communication between enterprises- 
employers and personnel, identify employees' problems and concerns and search for ways to solve them. In other words, building a powerful corporate HR brand.

\section{Methods}

The researchers carried out the benchmarking analysis of the existing mechanisms for attracting and retaining personnel in the forest industry. It revealed the bestimplemented HR branding practices of the largest enterprises in the industry. The goal of the analysis was to develop an HR brand for the forestry sector. The following companies were included in the analysis:

- Stora Enso, the largest Finnish-Swedish forestry company;

- International Paper, an international paper manufacturer;

- UPM-Kymmene Oyj, a Finnish forest industry company,

- Sveza Group of Companies, a Russian plywood manufacturer;

- West Fraser Timber Co. Ltd, a Canadian forestry company.

The data from Perm Pulp and Paper Plant provided insight into Perm Krai's experience in HR branding. The region was selected due to objective reasons. Perm Krai is a leading forest industry region in the Volga Federal District. Rosstat, Federal State Statistic Service, counted 513 forestry enterprises in the region at the end of 2018. According to the Service, the average number of workers employed in the timber industry in Perm Krai accounted for 19.4 thousand people in January-February of 2020.

Since Perm Pulp and Paper Plant is concerned about attracting young professionals to work at the company, it was selected for the research. The company is a member of ongoing cooperation with Perm educational institutions within the vocational program framework "School - secondary vocational school - universities enterprise".

The researchers conducted two opinion polls. The first survey was aimed at assessing the degree of Perm Pulp and Paper Plant's recognition among the residents of the Krai. The total sample included 207 respondents: $59.4 \%$ male and $40.6 \%$ female. The age-related composition of the respondents broke down to $6.8 \%$ aged 16 to 18 years old, $8.7 \%$ from 18 to $20 ; 64.3 \%$ from 20 to 22 ; and $20.3 \%$ over 22 . The survey was conducted on the Google Forms platform for 20 days (4-24) in May 2020.

The second survey was conducted to analyze the effectiveness of the Bumfest HR event implemented by the company. The total sample consisted of 87 people (direct participants): $65.5 \%$ male and $34.5 \%$ female. The age-related composition of the respondents included $85.1 \%$ aged 20 to $25 ; 9.2 \%$ under the age of 20 and $5.7 \%$ aged 25 to 35 . The survey was conducted on the Google Forms platform for 7 days (16-22) in December 2019.
Perm Pulp and Paper Plan held the Boomfest Forum as part of its HR brand strategy to create the image of the engineering profession that young people would appreciate. The forum engaged college and university students in a game where they had to develop a unique product made of cardboard. Besides, the forum included four educational blocks: a discussion "10 myths about the paper", two masterclasses "Creative Thinking" and "Over-professional skills", and a lecture "Industry 4.0".

\section{Results}

Benchmarking analysis, the study of the benchmark achievements of competing companies is an effective tool for using third-party experience to optimize a company's business processes [13]. In this research, the benchmarking analysis has enabled us to compare innovative practices and areas of HR branding in the forestry industry:

1) Openness of the production process. Stora Enso, the Finnish-Swedish forestry, implemented the practice to attract young professionals. Together with the employment agency Maximum, the company announced the "Global Trainee Program". The program offered potential candidates the opportunity to learn the specifics of the production process and internal communication by reading interns' blogs and private chats. Personal text messages and live video footage from the production sites reduced the level of anxiety among potential employees and formed a complete picture of ongoing events in the production process.

2) Labor protection and safety. Stora Enso presented the Safety Week program. As part of the program, Enocell and Uimaharju Sawmill Branches in Finland organized classes at local schools. The Langerbrugge Mill Belgium subsidiary focused on road safety by providing employees with VR technology to test their driving skills with a drunk simulator. Wood Supply Sweden launched new safety signs and developed communication materials about the most serious risks in the workplace. The Murrow sawmills in Poland and Nebolchi in Russia organized a drawing competition for preschool children. Nebolchi also focused on environmental safety.

3) Inclusiveness. The International Paper, an international paper producer, implemented programs that ensured equal accessibility conditions for employees with special needs. The company established a Global Diversity \& Inclusion Council focused on a multicultural strategy in the industrial sector.

4) Two-way communication between a manager and a subordinate. The Finnish company UPM developed additional communication means aimed at improving the interaction between the company's management and subordinates. For example, a production manager at the Oklahoma sawmill explained what his job included, what he did on a typical working day, and what he considered the best part of his job at UPM. A team leader at Cross SBU Supply, Magazine in Germany, 
highlighted diversity, career opportunities, and multiculturalism as the best aspects of working for UPM. He believed that the ever-changing market conditions in the forestry sector make the job challenging. Barrier-free communication minimizes manager-subordinate conflicts and strengthens corporate culture in terms of monitoring employee expectations.

5) Adaptation of new employees. To simplify the adaptation period for new employees, Sveza, the largest plywood producer in Russia, introduced Dasha chatbot, a virtual assistant on the Teams platform, and VKontakte social network. The online assistant accompanies new employees throughout the entire adaptation period (3 months), provides the necessary information about the company, notifies them about scheduled meetings, and answers all questions. Today, it has become a global trend to use social media to facilitate the adaptation of "newcomers" to the company [14].

6) Taking care of retired employees. The Canadian forest company West Fraser Timber Co. Ltd. provides all employees with a stock purchase plan and helps save money for retirement by making contributions to a defined benefit plan. In 2020, West Fraser Timber Co. Ltd. was included in the list of Canada's Top 100 Employers.

The analysis of HR branding practices in Perm Krai forest industry indicated the following features. The conducted sociological survey indicated that Perm Pulp and Paper Plant was not included in the top list of Perm residents' preferences about a potential place of work. The three most demanded job places presented oil and gas companies Gazprom Mezhregiongaz Perm (39\%) and LUKOIL-PERM (35\%), and PROMOBOT (26\%), a robotics company. Though Perm Pulp and Paper Plant recognition amounted to $47 \%$, only $7 \%$ of respondents considered the enterprise as a potential place of work.

Residents of Perm ranged the order of job selection criteria as follows:

- salary (20\%);

- company' reputation in the labor market (20\%);

- prestige of working for the company $(16 \%)$;

- social security $(16 \%)$;

- corporate training $(16 \%)$.

The "Boomfest", a role-based forum, can be considered a relatively successful practice of Perm Pulp and Paper Plant HR branding: 59\% of respondents gave the organizers the maximum rate for the event, $77.3 \%$ of participants said that they gained new experience and $52.6 \%$ of respondents reflected a positive change in their attitude towards the company after the event. However, the aim of achieving the company's maximum recognition and prestige as an employer was not accomplished. Even though, the image of an employer is one of the most significant factors for students as prospective job seekers [15].

\section{Conclusion}

The identified problem of respondents' unwillingness to apply for a job in the regional forest industry due to its low prestige value requires complex and long-term solution mechanisms. Some of them could be borrowed from a bank of ideas implemented by the largest Russian and foreign forestry companies. Some HR branding know-hows require significant investment, while others are comparatively less expensive but no less efficient. Thus, there is the need to develop an innovative HR brand strategy for the regional forestry that could, on the one hand, meet the demands of potential job seekers, primarily from local communities, and on the other hand, satisfy the demands of business that is interested in cost, time and labor savings to implement innovations.

\section{References}

1. T. Ambler, S. Barrow, J. Brand. Manag. 4 (1996)

2. T. Arkova, Bulletin of the Astrakhan State Technical University. Series: Economics. 1 (2011)

3. 3.D. Martasov, L. Danchenok, Business Imperatives (Kemerovo Institute of Plekhanov Russian University of Economics, Kemerovo, 2017)

4. K. Fernholz Trends in green jobs in the forest sector in the UNECE region (United Nations Publications, Geneva, 2019)

5. P. Katila, C. Pierce Colfer, W. De Jong, G. Galloway, P. Pacheco \& G. Winkel Sustainable Development Goals: Their Impacts on Forests and People (Cambridge University Press, Cambridge, 2019)

6. C. Ackerknecht, Unasylva. 61 (2010)

7. A. Veselova, E. Kerzina, Actual problems of the humanities and natural sciences. 9 (2014)

8. A. Sumchenko, I. Zinovieva, Modern high technologies. 10 (2013)

9. K. Backhaus, S. Tikoo, Career Dev. Int. 9 (2004)

10. G. Sukhanov, A. Kostylev, Forestry Journal. 2 (2016)

11. P. Blombäg, P. Poschen, M. Lövgren Employment Trends and Prospects in the European Forest Sector (United Nations Publications, Geneva, 2003)

12. B. Strehlke, Commonw. For. Rev. E 75, 3 (1996)

13. V. Revyakina, O. Starodubtseva, Infrastructure sectors of the economy: problems and development prospects. 9 (2015)

14. Z. Yuan, N. Li, Y. Mai, Z. Ye, J (J) Yu, Hum Resour Manage. 59 (2020) 
15. J.H. Wayne, W.J. Casper, Hum. Resour. Manage. 51 (2012) 